\title{
Education, survival and avoidable deaths in cancer patients in Finland
}

\author{
A Pokhrel,', P Martikainen², E Pukkala', M Rautalahti ${ }^{3}$, K Seppä' and T Hakulinen' \\ 'Finnish Cancer Registry, Institute for Statistical and Epidemiological Cancer Research, Pieni Roobertinkatu 9, Fl-00 I 30, Helsinki, Finland; ${ }^{2}$ Department \\ of Sociology, Fl-000 14 University of Helsinki, Helsinki, Finland; ${ }^{3}$ Cancer Society of Finland, Pieni Roobertinkatu 9, Fl-00 I 30, Helsinki, Finland
}

\begin{abstract}
BACKGROUND: Relative survival after cancer in Finland is at the highest level observed in Europe and has, in general, been on a steady increase. The aim of this study is to assess whether the high survival is equally shared by different population subgroups and to estimate the possible gains that might be achieved if equity prevailed.

MATERIALS AND METHODS: The educational level and occupation before the cancer diagnosis of patients diagnosed in Finland in 197 I-2005 was derived from an antecedent population census. The cancers were divided into 27 site categories. Cancer (cause)specific 5-year survival proportions were calculated for three patient categories based on the educational level and for an occupational group of potentially health-conscious patients (physicians, nurses, teachers etc.). Proportions of avoidable deaths were derived by assuming that the patients from the two lower education categories would have the same mortality owing to cancer, as those from the highest educational category. Estimates were also made by additionally assuming that even the mortalities owing to other causes of death were all equal to those in the highest category.

RESULTS: For almost all the sites considered, survival was consistently highest for patients with the highest education and lowest for those with only basic education. The potentially health-conscious patients had an even higher survival. The differences were, in part, attributable to less favourable distributions of tumour stages in the lower education categories. In 1996-2005, 4-7\% of the deaths in Finnish cancer patients could have potentially been avoided during the first 5-year period after diagnosis, if all the patients had the same cancer mortality as the patients with the highest educational background. The proportion would have also been much higher, $8-11 \%$, if, in addition, the mortality from other causes had been the same as that in the highest educational category.

INTERPRETATION: Even in a potentially equitable society with high health care standards, marked inequalities persist in cancer survival. Earlier cancer diagnosis and the ability to cope within the health care system may be a partly relevant explanation, but personal habits and lifestyles also have a role, particularly for the cancer patients' mortality from other causes of death than cancer.

British Journal of Cancer (2010) 103, I I09- III4. doi: I0.1038/sj.bjc.660586 I www.bjcancer.com
\end{abstract}

Published online 17 August 2010

(c) 2010 Cancer Research UK

Keywords: survival after cancer; social inequality; educational position; equity; avoidable deaths

Finland has one of the highest relative survival for cancer patients in Europe (Capocaccia et al, 2009). Studies in Denmark and the UK, countries with lower relative survival than in Finland, showed fairly large and consistent survival differences between educational and social groups (Shack et al, 2007; Dalton et al, 2008; Rachet et al, 2008). Increased survival does not necessarily mean the eradication of survival differences between subgroups (Coleman et al, 2008). Studies in Finland have demonstrated systematic differences by social class in cancer survival (Karjalainen and Pukkala, 1990; Auvinen, 1992; Auvinen et al, 1995; Dickman et al, 1997). It is important to determine whether these differences exist and their size, to plan actions on the basis of their likely causes from which they might have emerged. The causes for educational survival differences may be related to, e.g., behavioural characteristics, tumour stage at diagnosis or the health care system (Dalton et al, 2008).

*Correspondence: Dr A Pokhrel; E-mail: arun.pokhrel@cancer.fi Received 5 May 20I0; revised 12 July 20I0; accepted 22 July 20I0; published online 17 August 2010
The aim of the present study is to explore systematic social differences in cancer survival in Finland and how it has changed over time. Educational level was selected as the main variable defining the social subgroups, as it has been shown to strongly predict cancer survival in Denmark (Dalton et al, 2008) and as its definition has remained comparable over time. The impact of these differences was demonstrated by numbers and proportions of potentially avoidable deaths under the assumption of causespecific survival in all educational groups being equal to that in the subgroup with the highest education.

\section{MATERIALS AND METHODS}

Patients diagnosed with cancer in 1971-2005 and registered by the countrywide Finnish Cancer Registry were linked, through the use of the unique personal identity codes with the population censuses done every 5 years in 1970-2000, to obtain information on patients' educational levels and occupations (Pukkala et al, 2009). Persons born in 1906-80 were included in the analyses. Using the most recent antecedent information from census, the 
educational levels were divided into three categories according to the highest attained educational degree or certificate as follows: basic (lasting typically $<10$ years), secondary $(10-12$ years) and high education (13 years or more). Patients below 25 years of age were excluded as their educational level was not necessarily the final one.

Occupational details were used to create a supplementary group that should be particularly conscious of their health and cancer care possibilities, namely persons in medical and nursing work, teaching work, research and physical education. In comparative analyses involving in this category, such individuals were excluded from the educational categories (mainly from the high educational category) to form a fourth group. Cancers were divided into 27 site categories (Table 1). The patients were followed up from diagnosis until death, emigration or to the end of 2005, whichever came first: for a few $(0.13 \%)$, the follow-up was terminated owing to emigration.

The main outcome measure of the patients was the cancer (cause)-specific 5-year survival, where deaths owing to causes other than the cancer of the patients are counted as events censoring the follow-up time. The Cancer Registry corrects, when necessary, the official cause-of-death information, as it has more information than the person signing the death certificate (Hakulinen and Teppo, 1977). The Registry receives, on average, five notifications per cancer case, and registration is regarded as reliable both in diagnostic accuracy and completeness (Teppo et al, 1994; Curado et al, 2007).

The relative survival ratio, another measure preferred by population based cancer registries in estimating the cause-specific survival without relying on the quality of death certificates, was used for comparison (Ederer et al, 1961). Here, mortality owing to competing causes of death other than the patient's cancer is estimated as an overall mortality from the general population life tables by sex, age and calendar period. A linkage between a $20 \%$ random sample of the individuals from the censuses of 1970-2000 with the register of deaths and emigrations made it possible to also obtain general population mortality rates in the three educational categories. Thus, differences in general mortality by educational category were taken into account in relative survival analyses. For comparison, relative survival analyses without accounting for educational level were also conducted. The estimation of relative survival was based on the method of Hakulinen (1982).

Traditional direct age-standardisation was used for survival comparisons between the educational groups, as the groups differed in age structures (Pokhrel and Hakulinen, 2008); age structure of all patients diagnosed in 1971-2005 was used as a standard for each site. The ages used in the standardisation were $25-44,45-54,55-64,65-74$ and 75 years and more. This method maintained the interpretability of the standardised figures and the comparability between calendar periods, genders and educational categories within a cancer site but not between sites. Results were calculated for patient diagnosed in the periods 1971-85, 1986-95 and 1996-2005.

To study and control simultaneously for all prognostic variables, the regression model of Hakulinen and Tenkanen (1987) was used for the cancer (cause)-specific and relative survival analyses. For the former, the expected survival was defined to be uniformly one. The models included five annual follow-up intervals, sex, age (the same categories as in age-standardisation), calendar period (the three periods mentioned) and educational level (three categories). In some analyses, the tumour stage was also included as a covariate. Localised tumours were always classified separately

Table I Age-standardised 5-year cancer-specific survival proportions for the cancer patients diagnosed in Finland in 1996-2005 by site, sex and educational level (high, secondary, basic) and differences (in \% units) between the high and basic categories, by site and period. Patients' site-specific age distributions in 1971-2005 have been used as site-specific standards (both genders combined)

\begin{tabular}{|c|c|c|c|c|c|c|c|c|c|c|}
\hline Site & ICD-I 0 code & \multicolumn{4}{|c|}{ Males } & \multicolumn{4}{|c|}{ Females } & Number (197I-2005) \\
\hline Lip & $\mathrm{COO}$ & 98.5 & 98.3 & 97.0 & 1.5 & 96.4 & 99.2 & 97.9 & -1.5 & 4212 \\
\hline Stomach & $\mathrm{Cl} 6$ & 28.8 & 25.2 & 24.0 & 4.7 & 29.2 & 30.0 & 29.9 & -0.7 & 26958 \\
\hline Colon & $\mathrm{Cl} 8$ & 54.8 & 57.9 & 54.5 & 0.3 & 60.1 & 61.1 & 55.8 & 4.3 & 28759 \\
\hline Rectum & C19-20 & 59.8 & 55.7 & 52.7 & 7.1 & 62.4 & 57.1 & 56.8 & 5.6 & 19448 \\
\hline Pancreas & $\mathrm{C} 25$ & NA & NA & NA & NA & NA & 3.6 & 2.6 & NA & 19328 \\
\hline Nose & $C 30-31$ & NA & NA & NA & NA & 62.8 & 64.2 & 57.9 & 4.8 & 960 \\
\hline Lung & $C 33-34$ & 10.6 & 9.5 & 9.2 & 1.3 & 18.8 & 13.5 & 12.3 & 6.5 & 66014 \\
\hline Skin, melanoma & C43 & 82.7 & 78.2 & 77.4 & 5.3 & 91.9 & 88.6 & 84.5 & 7.4 & 14750 \\
\hline Skin, non-melanoma & C44 & 98.0 & 94.6 & 95.8 & 2.1 & 97.6 & 98.8 & 95.5 & 2.1 & 15383 \\
\hline Soft tissue & C $48-49$ & 67.4 & NA & 47.1 & 20.3 & 62.6 & 60.2 & 60.7 & 1.9 & 3468 \\
\hline Breast & C50 & - & - & - & - & 89.4 & 87.1 & 84.9 & 4.5 & 78292 \\
\hline Kidney & C $64-65$ & 61.1 & 58.9 & 55.2 & 5.9 & 62.1 & 63.6 & 60.8 & 1.3 & 18117 \\
\hline Urinary bladder & C67-68 & 80.7 & 78.2 & 76.8 & 3.9 & 83.3 & 77.8 & 69.7 & 13.5 & 18037 \\
\hline Thyroid & C73 & 84.2 & 85.9 & 82.6 & 1.5 & 93.9 & 92.6 & 91.1 & 2.8 & 8066 \\
\hline Hodgkin's lymphoma & C8I & 86.8 & NA & 83.4 & 3.3 & 86.2 & 86.3 & 82.5 & 3.7 & 3099 \\
\hline Non-Hodgkin's lymphoma & C82-85, C96 & 59.8 & 52.4 & 51.1 & 8.7 & 65.8 & 59.4 & 56.6 & 9.2 & 18818 \\
\hline Multiple myeloma & C90 & 40.5 & 36.3 & 25.4 & $|5|$. & 37.4 & 29.5 & 29.3 & 8.1 & 7023 \\
\hline Leukaemia & C91-95 & 49.3 & 47.9 & 40.1 & 9.1 & 45.2 & 38.8 & 39.1 & 6.0 & 11865 \\
\hline Other cancers & & 39.2 & 40.0 & 33.3 & 5.8 & 44.5 & 39.6 & 34.7 & 9.8 & 47905 \\
\hline Total & & & & & & & & & & $526 \mid 43$ \\
\hline
\end{tabular}

Abbreviation: NA = not estimable; sec = secondary; ICD = international classification of diseases; Diff= differences. Total numbers of cancer patients in 197 I -2005 by site are also given. 
and those remaining were divided into 1-4 categories (regional metastases; distant metastases; non-localised, extent unknown; unknown) depending on the site; the unknown stage category comprised of $10-20 \%$ of tumours.

Interactions between age and follow-up year, and age and stage were applied in all models including age and stage to allow for non-proportional cause-specific or excess hazards by these variables (Dickman et al, 2004). Cause-specific survival model results are reported as relative risks (RRs) of cause-specific death for a given category compared with a chosen reference category. The corresponding quantities for relative survival models, the relative risks of (cancer-related) excess mortality or the relative excess risk (RER) of death were also derived.

Numbers and proportions of potentially avoidable deaths were calculated for each educational group by assuming that the ageand sex-specific hazards of dying were equal to those in the high educational category by cancer site and cause of death (cancer of the patients, other causes of death). First, the assumption was made for cancer-specific mortality only. Second, the mortality owing to the competing risks of death was, in addition, assumed to be on the level observed in the high educational category. The numbers of avoidable deaths for all sites combined were obtained by summing the site-specific numbers. The theory of competing risks of death (Chiang, 1968) was used to obtain the diseasespecific ('crude') probabilities of death needed in a hypothetical situation of reduced cause-specific mortality.

\section{RESULTS}

The educational level could be identified from the censuses for $99.2 \%$ of patients; those with unknown education were excluded. Altogether, 526143 patients were included in the analyses (Table 1). Patients with basic education tended to be older than those with a high education, and the educational level increased in the population by calendar time.

The group with a high educational level had a higher agestandardised cancer-specific 5-year survival than that with basic educational level, almost without exception (Table 1). The age-specific and, thereby, also the age-standardised 5-year cancer-specific survival proportions and their differences could not be estimated for every educational group in 1996-2005 for five sites in males and four sites in females. Statistical modelling showed that the higher survival among the highly educated had persisted over calendar time. Differences in RRs of cancer-specific mortality between the educational categories were larger when the stage was not included in the model, and existed only when that RR was under 0.85 (Figure 1). In other words, when there was a larger mortality difference related to educational level, it was partly accounted for by differences in stage distribution, almost regardless of the site. The attenuation of the relative differences varied strongly but was, with the exception of testicular and kidney cancers, quite modest. The health-conscious occupational group still clearly had a more favourable cancer-specific survival than the rest of the high education category (Figure 2). The RRs of this group were also somewhat attenuated when the stage was adjusted for by the model compared with the results derived without adjusting for the stage.

The relative survival analysis, where the baseline general mortality had been calculated specific to the educational category, mostly gave similar results (RER) to those (RR) of the causespecific analyses (results not shown). Not using comparable baseline mortality with respect to educational category resulted in larger differences between the RERs and the RRs, which also held true when stage was taken into account in the model.

If in the most recent period 1996-2005, the cancer-specific mortality of all male and female patients equalled that of the high education group, $8 \%$ of cancer deaths in patients diagnosed at ages 25-64 years during the first 5 years after diagnosis are theoretically avoidable (Table 2). For ages $65-89$, the corresponding proportion is higher, $10 \%$; these proportions are lower, $7 \%$, when prostate and breast cancers are excluded. When the same estimation is done for the first 10 years after diagnosis, the numbers and proportions of avoidable cancer deaths decrease. At 25-64 years, the proportions of avoidable deaths were fairly stable over time. In contrast, in the first 5-year follow-up period after diagnosis, there has been a clear increase in them at ages 65-89 years, even when prostate and breast cancers are excluded. There

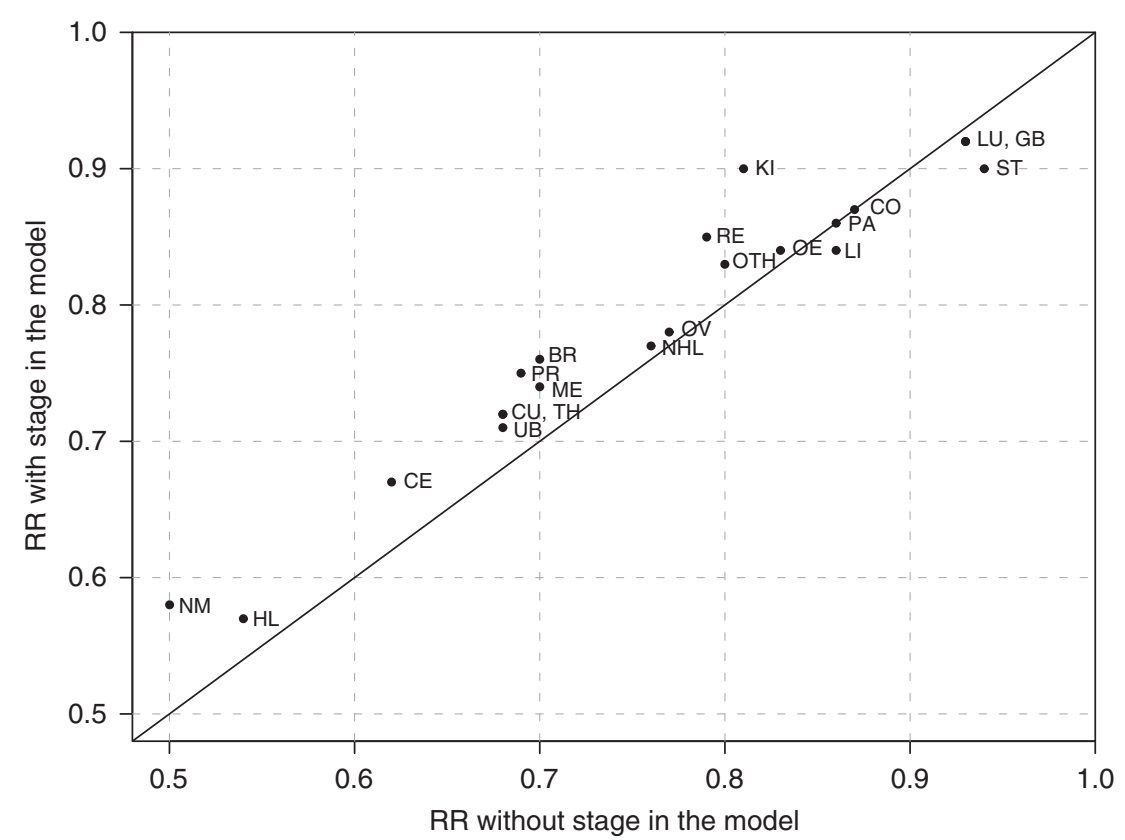

Figure I Risk ratios for cancer death of patients diagnosed in 1971-2005 (high vs basic education) without and with accounting for stage, by site (sites: $\mathrm{OE}=$ oesophagus; $\mathrm{ST}=$ stomach; $\mathrm{CO}=$ colon; $\mathrm{RE}=$ rectum; $\mathrm{LI}=$ liver; $\mathrm{GB}=$ gallbladder; $\mathrm{PA}=$ pancreas; $\mathrm{LU}=$ lung; $M E=$ skin, melanoma; $N M=$ skin, non-melanoma; $\mathrm{BR}=$ breast; $\mathrm{CE}=$ cervix uteri; $\mathrm{CU}=$ corpus uteri; $\mathrm{OV}=$ ovary; $\mathrm{PR}=$ prostate; $\mathrm{KI}=$ kidney; $\mathrm{UB}=$ urinary bladder; $\mathrm{TH}=$ thyroid; $\mathrm{HL}=$ Hodgkin's lymphoma; $\mathrm{NHL}=$ non-Hodgkin's lymphoma; OTH=other cancers as specified in Table I). The model accounts for gender where applicable. The diagonal indicates equality of the two RRs. Results are shown for sites with model convergence only. 


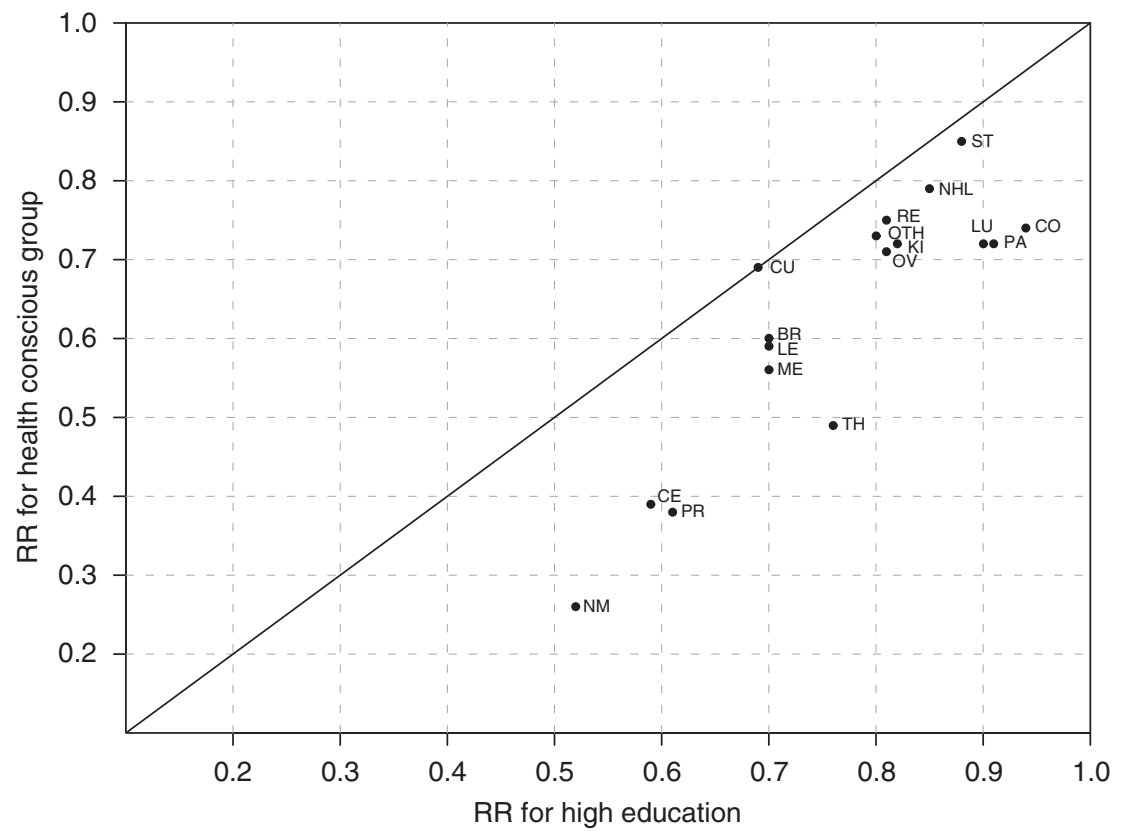

Figure 2 Risk ratios for cancer death high vs basic education and health-conscious occupational group vs basic education and for patients diagnosed in 1996-2005, by site (sites: ST= stomach; $C O=$ colon; $R E=$ rectum; $P A=$ pancreas; $L U=$ lung; $M E=$ skin, melanoma; $N M=$ skin, non-melanoma; $\mathrm{BR}=$ breast; $\mathrm{CE}=$ cervix uteri; $\mathrm{CU}=$ corpus uteri; $\mathrm{OV}=$ ovary; $\mathrm{PR}=$ prostate; $\mathrm{KI}=$ kidney; $\mathrm{TH}=$ thyroid; $\mathrm{NHL}=$ non-Hodgkin's lymphoma; $\mathrm{LE}=$ leukaemia; $\mathrm{OTH}=$ other cancers as specified in Table I). The model accounts for gender where applicable. Persons in the health-conscious occupational group have been removed from the education categories. The diagonal indicates equality of the two RRs.

Table 2 Number $(N)$ and proportion (\%) of potentially avoidable cancer deaths in Finland by period, age and site in a hypothetical situation where all patients would have the same cancer-specific mortality as those with a high education

\begin{tabular}{|c|c|c|c|c|c|c|c|c|c|c|c|c|}
\hline \multirow{2}{*}{ Age/site } & \multicolumn{4}{|c|}{$|97|-\mid 985$} & \multicolumn{4}{|c|}{$1986-1995$} & \multicolumn{4}{|c|}{$1996-2005$} \\
\hline & \multicolumn{2}{|c|}{ 5-year } & \multicolumn{2}{|c|}{ 10-year } & \multicolumn{2}{|c|}{ 5-year } & \multicolumn{2}{|c|}{ 10-year } & \multicolumn{2}{|c|}{ 5-year } & \multicolumn{2}{|c|}{ 10-year } \\
\hline \multicolumn{13}{|l|}{$25-64$ years } \\
\hline Stomach & 64 & । & 87 & 2 & -5 & 0 & 19 & । & -8 & -1 & -30 & -2 \\
\hline Colon and rectum & 162 & 5 & 197 & 6 & 324 & 15 & 339 & 14 & 83 & 3 & 35 & 1 \\
\hline Skin, non-melanoma & 36 & 59 & 43 & 63 & 21 & 76 & 21 & 61 & 10 & 29 & 15 & 38 \\
\hline Breast & 358 & 10 & 534 & 11 & 530 & 22 & 516 & 14 & 356 & 17 & 387 & 11 \\
\hline Female genital organs & 537 & 20 & 512 & 17 & 208 & 13 & 241 & 13 & 197 & 13 & 216 & 11 \\
\hline Prostate & 96 & 11 & 75 & 7 & $|4|$ & 16 & 136 & 12 & 303 & 27 & 369 & 20 \\
\hline Urinary organs & 390 & 20 & 428 & 19 & 183 & 13 & 220 & 14 & 37 & 3 & -58 & -4 \\
\hline Leukaemia & 62 & 4 & 99 & 6 & 6 & । & 46 & 5 & 150 & 23 & 144 & 18 \\
\hline Non-Hodgkin's lymphoma & 102 & 8 & 39 & 3 & 107 & 10 & 115 & 8 & 195 & 18 & 104 & 7 \\
\hline \multicolumn{13}{|l|}{$65-89$ years } \\
\hline Stomach & 121 & 3 & 48 & । & 131 & 3 & 112 & 2 & 192 & 5 & 186 & 5 \\
\hline Colon and rectum & 168 & 6 & 243 & 8 & 495 & 9 & 463 & 8 & 504 & 8 & 395 & 6 \\
\hline Lung & 69 & । & 66 & । & 201 & 2 & 192 & 2 & 180 & I & 109 & । \\
\hline Skin, melanoma & 36 & 17 & 20 & 8 & 63 & 16 & 72 & 15 & 102 & 17 & 39 & 6 \\
\hline Skin, non-melanoma & -3 & -4 & 3 & 5 & 46 & 33 & 60 & 37 & 93 & 43 & 102 & 45 \\
\hline Breast & 224 & 18 & 253 & 15 & 550 & 28 & 718 & 27 & 616 & 26 & 408 & 12 \\
\hline Female genital organs & 222 & 15 & 214 & 13 & 311 & 12 & 293 & 11 & 599 & 22 & 506 & 17 \\
\hline Prostate & 137 & 8 & 39 & 2 & 541 & 15 & 617 & 13 & 1397 & 31 & 1764 & 25 \\
\hline Urinary organs & 243 & 16 & 241 & 14 & 438 & 16 & 467 & 15 & 490 & 15 & 487 & 13 \\
\hline Leukaemia & 27 & 3 & 67 & 6 & -24 & -2 & -20 & -1 & 23 & 1 & 97 & 5 \\
\hline Non-Hodgkin's lymphoma & $|4|$ & 17 & 176 & 19 & 193 & 9 & $17 \mid$ & 8 & 466 & 17 & 351 & 12 \\
\hline Other sites & 290 & 3 & 357 & 4 & 785 & 5 & 744 & 5 & $135 \mid$ & 7 & 1293 & 6 \\
\hline Total & 1675 & 5 & 1727 & 5 & 3730 & 7 & 3889 & 7 & 6014 & 10 & 5737 & 9 \\
\hline
\end{tabular}


Table 3 Number $(N)$ and proportion (\%) of potentially avoidable deaths due to cancer and other causes in cancer patients in Finland in 1996-2005, by age, in two hypothetical situations: (A) all patients would have the same cancer-specific mortality and (B) same cancer and competing-risk mortality as those with a high education

\begin{tabular}{|c|c|c|c|c|c|c|c|c|c|c|c|c|}
\hline Age at cancer diagnosis & \multicolumn{4}{|c|}{ Cancer } & \multicolumn{4}{|c|}{ Other } & \multicolumn{4}{|c|}{ Total } \\
\hline \multicolumn{13}{|l|}{$\begin{array}{l}\text { A. Same cancer-specific mortality } \\
25-64 \text { years }\end{array}$} \\
\hline Total & 2188 & 8 & 2026 & 7 & -167 & -5 & -330 & -5 & 2021 & 7 & 1696 & 5 \\
\hline Total & 6014 & 10 & 5737 & 9 & $-137 \mid$ & -6 & -2480 & -7 & 4642 & 6 & 3257 & 3 \\
\hline Total excluding prostate and breast & 4001 & 7 & 3565 & 6 & -1062 & -7 & -1575 & -7 & 2939 & 4 & 1990 & 3 \\
\hline \multicolumn{13}{|c|}{$\begin{array}{l}\text { B. Same cancer-specific and competing-risk mortality } \\
25-64 \text { years }\end{array}$} \\
\hline Total & 1984 & 8 & 1703 & 6 & 963 & 27 & 1365 & 22 & 2947 & 10 & 3068 & 8 \\
\hline $\begin{array}{l}\text { Total excluding prostate and breast } \\
65-89 \text { years }\end{array}$ & 1339 & 6 & 986 & 4 & 713 & 28 & 957 & 23 & 2052 & 8 & 1943 & 7 \\
\hline
\end{tabular}

has been an increasing trend in avoidable cancer deaths for 10-year follow-up period after diagnosis, which almost disappears after excluding prostate and breast cancers. The numbers and proportions of potentially avoidable deaths varied greatly by cancer site (Table 2). Proportions exceeding 10\% were obtained for cancers of the skin, breast, female genital organs, prostate and urinary organs, whereas practically no or few avoidable deaths were obtained for stomach and lung cancers.

The avoidable cancer deaths will contribute to an increase in the number of persons exposed to competing causes of death, so, there will be negative numbers in the avoidable deaths owing to causes other than the cancer (Table 3, upper panel A). At ages 25-64 years, the total proportion of avoidable deaths is $5-7 \%$ in the first 5 years and about $3-5 \%$ in the first 10 -year period after diagnosis; at ages 65-89 years, the respective proportions are $4-6$ and $3 \%$.

By assuming that both the cancer-specific mortality and the mortality owing to other causes would be the same as those observed in patients with high education, the numbers and proportions of avoidable cancer deaths are slightly smaller than those without the assumption of an improved mortality from other causes of death (Table 3, lower panel B). On the other hand, marked numbers of avoidable deaths from other causes are obtained, ranging from 9 to $28 \%$. At ages 25-64 years, avoidable deaths, regardless of the cause, are $8-10 \%$ during the first 5 years of follow-up after diagnosis and $7-8 \%$ in the first 10 years; at ages 65-89 years, these proportions are $8-11$ and $6-8 \%$, respectively.

\section{DISCUSSION}

It has been previously shown and generally accepted that cancer incidence is strongly influenced by a person's social position or education, as the risk factors of cancer have not evenly distributed (Pukkala, 1995; Dalton et al, 2008). It is less easy to accept that cancer survival should depend on these factors as this may indicate differential access to care. Nordic countries, among them Finland, have been emphasising equality among residents as far as health care services are concerned. Cancer control plans have been made in Finland since 1952 to secure equal rights and potential access to services (Finnish Cancer Committee, 1984). Our study suggests that this goal has not been reached.

Social group differences in cancer survival have been seen wherever it has been studied (Kogevinas et al, 1997; Mackillop et al, 1997;
Rosso et al, 1997; Singh et al, 2003; Madison et al, 2004; Dejardin et al, 2006; Shack et al, 2007; Dalton et al, 2008; Rachet et al, 2008). Several factors related to risk profiles, tumour characteristics or the health system might lie behind these survival differences.

Risk-factor related risks of death may well be working to different extents for patient survival in different groups (Dalton et al, 2008). It is quite conceivable that cancer survival, not only survival with respect to competing causes of death, will depend on factors like smoking, alcohol use and nutritional status, which may also influence the available treatment options.

In a country with good equity in health services, it may sound implausible that health services are better targeted towards the more educated, but the less educated may well be less aware of early symptoms and may experience a delay in diagnosis (Auvinen et al, 1995; Neal and Allgar, 2005; Hansen et al, 2008). Indeed, when the stage distribution was adjusted for, the cancer-specific survival figures of the educational groups were closer.

Early detection by the prostate-specific antigen (PSA) test will increase the apparent survival for prostate cancer (Schröder et al, 2009), and higher educated persons may have more intense PSA diagnostics than others. There is also an increase in survival for breast cancer patients related to mammographic screening (Berry et al, 2005), and that may be associated with the education of patient due to differences in the proportion of participation. A higher education may help in navigating within the health system thus enabling better and more timely care. For example, a higher education of the patient can improve the patient-doctor interaction and the ability to follow care regimens. The fact that the health-conscious patient group (e.g., doctors, nurses, teachers) clearly had the highest cancer-specific survival figures points out that much is achievable, provided that their cancer outcomes could be achieved for everyone. Although higher educated patients may have better financial resources to obtain additional care from the private sector, in Finland this did not exist during the period studied.

The numbers and proportions of avoidable deaths have been used as a measure of what possibly could be achieved if cancer patients' relative survival could be raised to an optimal level defined by a higher survival in other subgroups (Dickman et al, 1997) or other populations (Abdel-Rahman et al, 2009). These quantities should be estimated regardless of the cause, as some of the persons saved from cancer death are likely to die from competing causes of death even within a 5- or 10-year period after 
diagnosis. The savings do not last long, as the competing-risk mortality will wear them off rapidly, depending on the age of the patients. Rather than 'avoidable' the term could be 'postponable' deaths, and person-years saved (Hakulinen and Teppo, 1976) or expected life years lost per patient might be more useful (Hakama and Hakulinen, 1977; Seppä and Hakulinen, 2009).

\section{CONCLUSION}

Clear educational differences in cancer patient survival are still observed in Finland, despite the level of survival being internationally very high and regardless of the very strong improvement in survival over the past decades.

\section{ACKNOWLEDGEMENTS}

This study was supported by a grant from the Cancer Society of Finland.

\section{Conflict of interest}

The authors declare no conflict of interest.

\section{REFERENCES}

Abdel-Rahman M, Stockton D, Rachet B, Hakulinen T, Coleman MP (2009) What if cancer survival in Britain were the same as in Europe: how many deaths are avoidable? Br J Cancer 101: s115-s124

Auvinen A (1992) Social class and colon cancer survival in Finland. Cancer 70: $402-409$

Auvinen A, Karjalainen S, Pukkala E (1995) Social class and cancer patient survival in Finland. Am J Epidemiol 142: 1089-1102

Berry DA, Cronin KA, Plevritis SK, Fryback DG, Clarke L, Zelen M, Mandelblatt JS, Yakovlev AY, Habbema JDF, Feuer EJ (2005) Effect of screening and adjuvant therapy on mortality from breast cancer. $\mathrm{N} \mathrm{Engl} \mathrm{J}$ Med 353: $1784-1792$

Capocaccia R, Gavin A, Hakulinen T, Lutz JM, Sant M (eds) (2009) Survival of cancer patients in Europe, 1995-2002: the EUROCARE 4 study. Eur J Cancer 45: $901-1094$

Chiang CL (1968) Introduction to Stochastic Processes in Biostatistics. Wiley: New York

Coleman MP, Quaresma M, Berrino F, Lutz JM, De Angelis R, Capocaccia R, Baili P, Rachet B, Gatta G, Hakulinen T, Micheli A, Sant M, Weir HK, Elwood JM, Tsukuma H, Koifman S, Azevedo e Silva G, Francisci S, Santaquilani M, Verdecchia A, Storm HH, Young JL, CONCORD Working Group (2008) Cancer Survival in five continents: a worldwide populationbased study (CONCORD). Lancet Oncol 9: 730-756

Curado MP, Edwards B, Shin HR, Storm H, Ferlay J, Heanue M, Boyle P (eds) (2007) Cancer Incidence in Five Continents Vol. IX. IARC Scientific Publications 160. International Agency for Research on Cancer: Lyon

Dalton SO, Schüz J, Johansen C, Kjaer SK, Engholm G, Storm HH, Olsen JH (eds) (2008) CANULI - Social inequality on cancer incidence and survival in Denmark. Eur J Cancer 44: 1933-2085

Dejardin O, Remontet L, Bouvier AM, Danzon A, Trétarre B, Delafosse P, Molinié F, Maarouf N, Velten M, Sauleau EA, Bourdon-Raverdy N, Grosclaude P, Boutreux S, De Pouvourville G, Launoy G (2006) Socioeconomic and geographic determinants of survival of patients with digestive cancer in France. Br J Cancer 95: 944-949

Dickman PW, Gibberd RW, Hakulinen T (1997) Estimating potential savings in cancer deaths by eliminating regional and social class variation in cancer survival in the Nordic countries. J Epidemiol Comm Health 51: 289-298

Dickman PW, Sloggett A, Hills M, Hakulinen T (2004) Regression models for relative survival. Stat Med 23: $51-64$

Ederer F, Axtell LM, Cutler SJ (1961) The relative survival rate: a statistical methodology. Natl Cancer Inst Monogr 6: 101-121

Finnish Cancer Committee (1984) Cancer - Occurrence, Risk Factors and Prevention, Vammala Printing House Ltd: Helsinki, pp 1-72.

Hakama M, Hakulinen T (1977) Estimating the expectation of life in cancer survival studies with incomplete follow-up information. J Chronic Dis 30: $585-597$

Hakulinen T (1982) Cancer survival corrected for heterogeneity in patient withdrawal. Biometrics 38: $933-942$

Hakulinen T, Tenkanen L (1987) Regression analysis of relative survival rates. Appl Stat 36: $309-317$

Hakulinen T, Teppo L (1976) The increase in working years due to elimination of cancer as a cause of death. Int J Cancer 17: 429-435
Hakulinen T, Teppo L (1977) Causes of death among female patients with cancer of the breast and intestines. Ann Clin Res 9: 15-24

Hansen RD, Olesen F, Sorensen HT, Sokolowski I, Sondergaard J (2008) Socioeconomic patient characteristics predict delay in cancer diagnosis: a Danish cohort study. BMC Health Serv Res 8: 49

Karjalainen S, Pukkala E (1990) Social class as a prognostic factor in breast cancer survival. Cancer 66: 819-826

Kogevinas M, Pearce N, Susser M, Boffetta P (1997) Social Inequalities and Cancer. IARC Scientific Publications 138. International Agency for Research on Cancer: Lyon

Mackillop WJ, Zhang-Salomons J, Groome PA, Paszat L, Holowaty E (1997) Socioeconomic status and cancer survival in Ontario. J Clin Oncol 15: $1680-1689$

Madison T, Schottenfeld D, James SA, Schwartz AG, Gruber SB (2004) Endometrial cancer: socioeconomic status and racial/ethnic differences in stage at diagnosis, treatment and survival. Am J Public Health 94: $2104-2111$

Neal RD, Allgar VL (2005) Sociodemographic factors and delays in the diagnosis of six cancers: analysis of data from the 'National Survey of NHS patients: Cancer'. Br J Cancer 92: $1971-1975$

Pokhrel A, Hakulinen T (2008) How to interpret relative survival ratios of cancer patients. Eur J Cancer 44: 2661 -2667

Pukkala E (1995) Cancer Risk by Social Class and Occupation. A Survey of 109000 Cancer Cases Among Finns of Working Age. Contributions to Epidemiology and Biostatistics. Vol 7 Karger: Basel

Pukkala E, Martinsen JI, Lynge E, Gunnarsdottir HK, Sparén P, Tryggvadottir L, Weiderpass E, Kjaerheim K (2009) Occupation and cancer-follow-up of 15 million people in five Nordic countries. Acta Oncol 48: 646-790

Rachet B, Woods LM, Mitry E, Riga M, Cooper N, Quinn MJ, Steward J, Brenner H, Estéve J, Sullivan R, Coleman MP (2008) Cancer survival in England and Wales at the end of the 20th century. Br J Cancer 99: $\mathrm{S} 2-\mathrm{S} 10$

Rosso S, Faggiano F, Zanetti R, Costa G (1997) Social class and cancer survival in Turin, Italy. J Epidemiol Comm Health 51: $30-34$

Schröder FH, Hugosson J, Roobol MJ, Tammela TLJ, Ciatto S, Nelen V, Kwiatkowski M, Lujan M, Lilja H, Zappa M, Denis LJ, Recker F, Berenguer A, Määttänen L, Bangma CH, Aus G, Villers A, Rebillard X, van der Kwast T, Blijenberg BG, Moss SM, de Koning HJ, Auvinen A, for the ERSPC Investigators (2009) Screening and prostate-cancer mortality in a randomized European study. $N$ Eng J Med 360: $1321-1328$

Seppä K, Hakulinen T (2009) Mean and median survival times of cancer patients should be corrected for informative censoring. J Clin Epidemiol 62: $1095-1102$

Shack LG, Rachet B, Brewster DH, Coleman MP (2007) Socioeconomic inequalities in cancer survival in Scotland. Br J Cancer 97: 999-1004

Singh GK, Miller BA, Hankey BF, Edwards BK (2003) Area Socioeconomic Variations in the US; Cancer Incidence, Mortality, Stage, Treatment, and Survival, 1975-1999. NCI Cancer Surveillance Monograph Series 4. National Cancer Institute: Bethesda, MD

Teppo L, Pukkala E, Lehtonen M (1994) Data quality and quality control of a population-based cancer registry. Acta Oncol 33: 365-369 